\title{
Normal Flow and Stopped Flow Injection Spectrophotometric Determination of Quercetin Dihydrate Dietary Supplements
}

\author{
Sadeem Subhi Abed ${ }^{1}$, Hinda Ali Mahmood ${ }^{2}$ \\ Department of Chemistry, College of Science, University of Baghdad, Baghdad, Iraq
}

\begin{abstract}
Simple and sensitive normal flow injection(nFI) and stopped-FI spectrophotometric methods for the determination of quercetin dehydrate $(\mathrm{QRC})$ in pure form were proposed, The methods were based on diazotization and coupling reaction between QRC and diazotized metoclopramide in alkaline medium to form orange-water soluble dye. The dye is stable and has a maximum absorbance

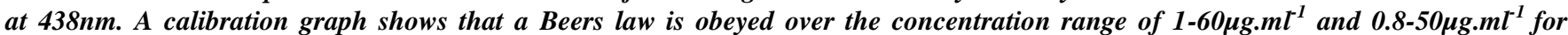
$(Q R C)$ with a detection limit is $0.4166 \mu \mathrm{g} . \mathrm{ml}^{-1}, 0.1338$ for $\mathrm{nFI}$ and stopped-FI methods, respectively. The reproducibility percentage (RSD\% is 1.528 and 1.695 for both $n F I$ and stopped-FI methods, and recovery percentage Rec\% is (101.527) for nFIA and (104.36) for stopped-FIA. In nFIA the chemical and physical parameters are studied. The proposed method was applied on dietary supplements such as (Mega quercetin, Quercetin dehydrate).
\end{abstract}

Keywords: Flavonoids, Quercetin dihydrate, spectrophotometric method, normal- Flow injection, Stopped flow injection

\section{Introduction}

Flavonoids are a specific class of phenolic plant phytochemicals represented by over 5000 compounds, subdivided into 13 categories that include anthocyanidins, catechins, flavonols, and flavones[1].The flavonol quercetin has shown much promise as an antioxidant agent, imparting a protective effect in reducing the risk of developing cardiovascular disease[2-4]. and certain types of cancer[5,6]. Quercetin dihydrate(QRC) is a type of flavonoids. Flavonoide possess the beneficial effect like antioxidant, anti-inflammatory, anti-platelet aggregatory activities and restore endothelial function and prevent LDL oxidation .Quercetein is found in redwine, green tea, onions, berries, citrus fruit, apples, garlic [7]. Since QRC is one of the most common flavonols and one of the most powerful antioxidants, it was important to develop a simple, precise and accurate method for the determination of QRC in different samples. Several methods were proposed in the literature to determine QRC in the samples of apple and tomato juice and fruits, wines, teas, serums and pharmaceutical preparations. These include HPLC [8-10], HPTLC [11] LC-MS [12], spectroscopic methods [13, 14], adsorptive stripping voltammetry [15], electro-chemical analysis [16] and fluorimetric methods [17]. The majority of methods required some pre-treatment of real samples, such as solid phase extraction [18] and molecularly imprinted polymers (MIPs).[19]

This paper describes spectrophotometric methods for determination of QRC by the diazotization coupling reactions with diazotized metoclopramide in alkaline medium. Metoclopramide was found to be a useful coupling reagents for diazotization reaction, because they produced a stable and rapid coupling organic products furthermore, these reagent is easily obtainable, highly purified and are soluble in ethanol therefore the proposed methods are considered as a new method for determination of flavonoids in flow injection method and stopped flow injection. In addition these methods have been satisfactorily applied for the determination of quercetin dihydrate in pure and pharmaceutical preparations.

\section{Experimental}

\subsection{Apparatus}

- All spectral and absorbance measurements were carried out by using Shimadzu UV/visible-260-digital double beam recording spectrophotometer using1-cm quarts cell (figure2).

- A flow cell with 50micro liter internal volume and $1 \mathrm{~cm}$ bath length was used for the absorbance measurements.

- A two-channel manifold was employed for the FI spectrophotometric determination of QRC.

- A peristaltic pump was used to transport the carries solutions.

- Injection valve was employed to appropriate injection volumes of standard solutions and samples.

- Flexible vinyl tubing of $0.5 \mathrm{~mm}$ internal diameter was used for the peristaltic pump. The peristaltic pump is interconnecting with a programmed timer which allows the flow to be stopped at a specific time after each injection (when the reacting mixture is in the detector flow cell) and then restarted to push the zone out of the detector.

- Reaction coil (RC) was of teflon with internal diameter of $0.5 \mathrm{~mm}$.

\subsection{Reagents}

1) Standard solution of QRC (M.wt=338.27g/mol) (CarlROTH), stock solution of $100 \mu \mathrm{g} . \mathrm{mL}^{-1}$ was prepared by dissolving $0.01 \mathrm{~g}$ of the pure compound in $50 \mathrm{ml}$ absolute ethanol and complete the volumetric flask by absolute ethanol.

2) Diazotized metoclopramide solution $(0.01 \mathrm{M})$ (General company for samarra drugs-Iraq): prepared daily by 


\section{International Journal of Science and Research (IJSR) \\ ISSN (Online): 2319-7064 \\ Index Copernicus Value (2016): 79.57 | Impact Factor (2015): 6.391}

dissolving $0.1772 \mathrm{gm}$ of metoclopramide in $3 \mathrm{ml}$ distilled water and $2.5 \mathrm{ml}$ hydrochloric acid (1M) $(\mathrm{BDH})$ in $50 \mathrm{ml}$ volumetric flask. Cool the mixture to $0-50 \mathrm{c}$ for $5 \mathrm{~min}$ using an ice bath. After $5 \mathrm{~min}$ add sodium nitrate (Merck) and stir the mixture. After $5 \mathrm{~min}$ the volume is completed to the mark with distilled water.

3) Sodium hydroxide $(\mathrm{BDH}):(0.1 \mathrm{M})$ : prepared by dissolving $1 \mathrm{gm}$ of the base in $250 \mathrm{ml}$ of distilled water.

4) Mega quercetin (Solary dietary supplements (USA)(1200mg/capsole) : Stock solution of $100 \mu \mathrm{g} . \mathrm{ml}^{-1}$ was prepared by dissolving of $0.01 \mathrm{~g}$ of the pure compound in $50 \mathrm{ml}$ absolute ethanol $(1.2 \mathrm{~g}$ in each capsole ) and complete the volume to the mark by absolute ethanol .

5) Quercetin dihydrate ) Bulk dietary supplements (USA) (100g (3.5302) : Stock solution of $100 \mu \mathrm{g} \cdot \mathrm{mL}^{-1}$ was prepared by dissolving $0.01 \mathrm{~g}$ of the pure compound in 50 $\mathrm{ml}$ absolute ethanol and complete the volumetric flask by absolute ethanol .

\subsection{General FIA procedure and stopped flow injection method}

The manifold used for the determination of QRC was designed to provide different reaction conditions for magnifying the absorbance signal generated by the reaction of the diazotized metoclopramide with QRC in sodium hydroxide medium. Maximum absorbance intensity was

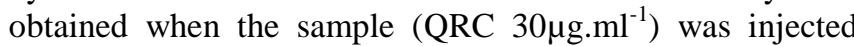
into a stream of diazotized metoclopramide $(0.005 \mathrm{M})$ and then mixed with sodium hydroxide $(0.1 \mathrm{M})$ and the maximum spectrum value was measured at $438 \mathrm{~nm}$ as given in (Figure 1), (Figure 2). The influence of different chemical and physical FIA parameters on the absorbance of the colored product was optimized as follows: QRC solution in the range of $0.7-60 \mu \mathrm{g} \cdot \mathrm{ml}^{-1}$ was prepared from the standard solution $\left(100 \mu \mathrm{g} \cdot \mathrm{mL}^{-1}\right)$. A $102 \mu \mathrm{L}$ of $30 \mu \mathrm{g} \cdot \mathrm{ml}^{-1} \mathrm{QRC}$ was injected into the stream of diazotized metoclopramide $(0.001 \mathrm{M})$ then the mixture combined with $(0.1 \mathrm{M}) \mathrm{NaOH}$ at T-link with total flow rate $2 \mathrm{ml} / \mathrm{min}$ for the two channels.

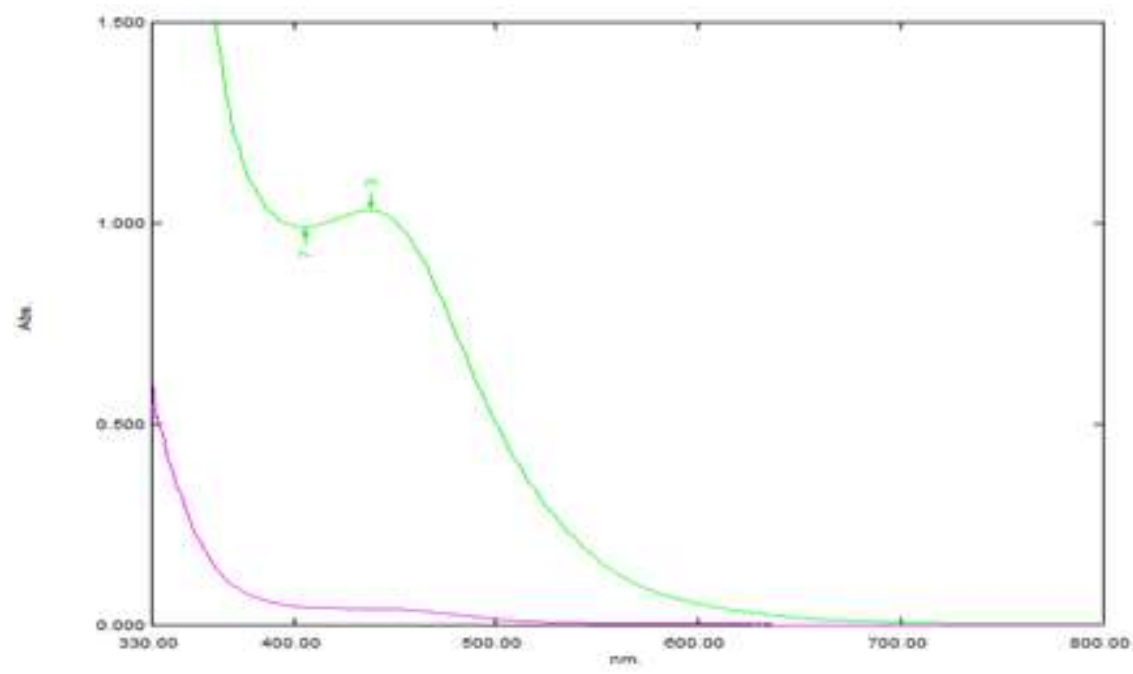

Figure 1: Absorption spectra of $\left(30 \mu \mathrm{g} \cdot \mathrm{ml}^{-1}\right) \mathrm{QRC}$ treated as described under procedure and measured against reagent blank $((0.01 \mathrm{~m})$ diazotized metoclopramide and $(0.1 \mathrm{M})$ sodium hydroxide $)$ and the reagent blank measured against distilled Water

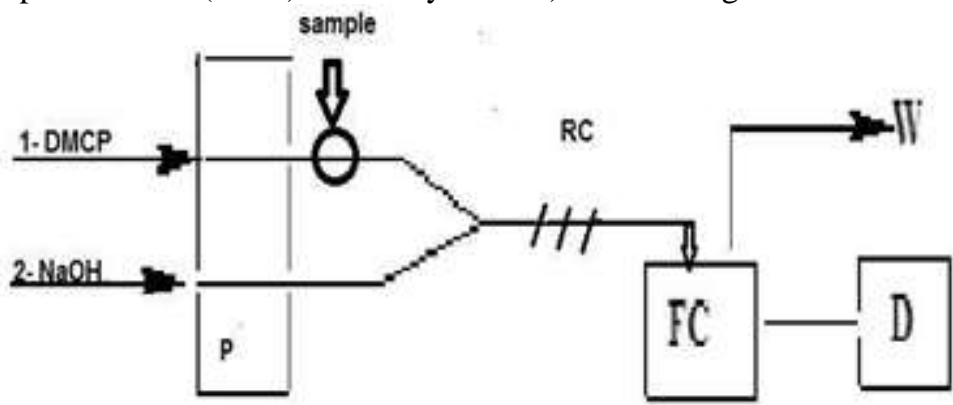

Figure 2: A schematic diagram of FIA manifold Where: (1) and (2), solutions of diazotized metoclopramide and sodium hydroxide respectively; $\mathrm{P}=$ peristaltic pump; Sample= injection sample $\mathrm{QRC} ; \mathrm{RC}=$ reaction coil; $\mathrm{Fc}=\mathrm{flow}$ cell; $\mathrm{D}=$ detector; $\mathrm{W}=$ waste

Stopped -FI procedure can increase the sensitivity by increasing the reaction time in a stopping period, there by promoting more product. There is a stopping of the flow to hold an injected zone of sample in a mixing coil for promoting the reaction to take place without dispersion of the resulting product. In kinetic methods, the flow is stopped into the detector flow cell to monitor the evolution of the reaction [20].
The stopped FI method can increase sensitivity of the measurement by increasing the residence (reaction) time, the elapsed time after sample and reagent are mixed together prior to detection of the reaction product. By stopping the flow the residence time can be prolonged without increasing the length of the reaction coil, thus avoiding an increase of dispersion [21, 22]

Volume 6 Issue 12, December 2017 www.ijsr.net 


\section{International Journal of Science and Research (IJSR) \\ ISSN (Online): 2319-7064 \\ Index Copernicus Value (2016): 79.57 | Impact Factor (2015): 6.391}

Travelling time " period from the injection to the stopping time" depend on the physical parameters in which increase with increase reaction coil and sample manifolds parameters, the travelling time after each injection was studies and it was found that the sample zone reached the flow cell $30 \mathrm{sec}$ after each injection, and the time intervals between stopping and restarting the pump flow, in the range(10-100sec) was also studies, it found after $50 \mathrm{sec}$ (Figure 3 ) the stopping time this time was selected as the optimum interval time.

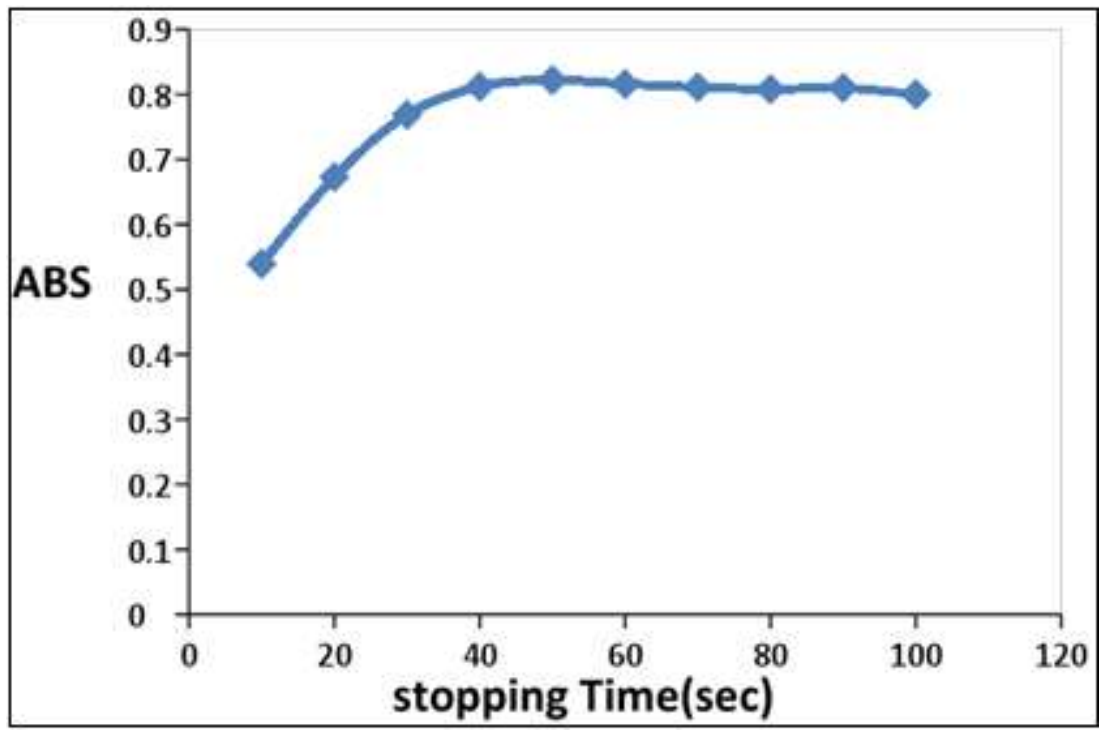

Figure 3: Effect of stopping time (sec)

\section{Results and Discussion}

The factors affecting on the sensitivity and stability of the colored diazotization coupling reaction between diazotized metoclopramide and QRC in an alkaline medium were carefully studied. . The influence of different chemical and physical FIA parameters on the absorbance of the colored product was optimized as followed :
Optimization of chemical parameters:

The influence of different chemical FIA parameters on the absorbance of the colored product was optimized as follows: The effect of different concentration of Diazotized metoclopramide was investigated. A concentration of $(0.005 \mathrm{M})$ of metoclopramide gave the highest absorbance and was chosen for further experiment (Figure 4).

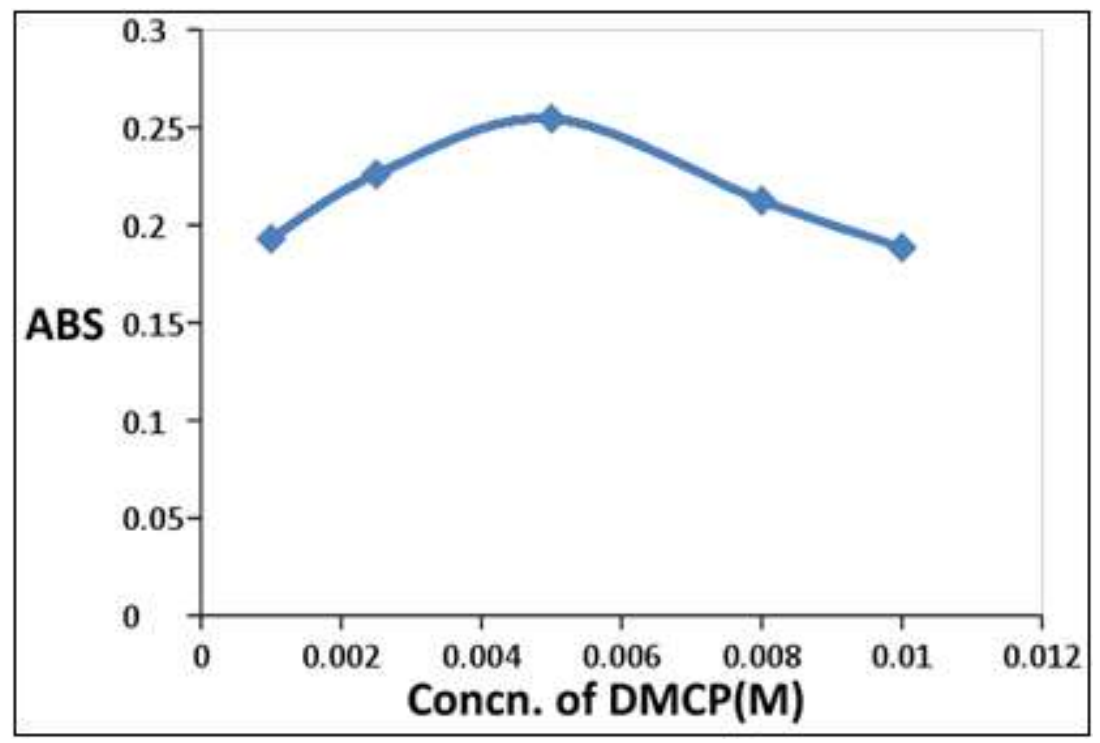

Figure 4: Effect of concentration of diazotized metoclopramide

It was observed that the reaction between diazotized metoclopramide and QRC depends on alkaline medium, The absorbance of the dye formed increased and became more stable in alkaline medium, therefore, the effect of different alkaline solutions $(0.1 \mathrm{M})$ on the colored product was studied such as sodium hydroxide, ammonium hydroxide, potassium hydroxide, sodium acetate and sodium carbonate. As shown in figure (5a) maximum sensitivity and stability were obtained only when the reaction was carried out in the presence of sodium hydroxide solution. The effect of different concentrations $(0.01-0.3 \mathrm{M})$ of $\mathrm{NaOH}(0.1 \mathrm{M})$ was studied. the effect of different concentrations of sodium hydroxide was studies and $0.1 \mathrm{M}$ was found to be the optimum (figure (5b).

Volume 6 Issue 12, December 2017 
International Journal of Science and Research (IJSR)

ISSN (Online): 2319-7064

Index Copernicus Value (2016): 79.57 | Impact Factor (2015): 6.391

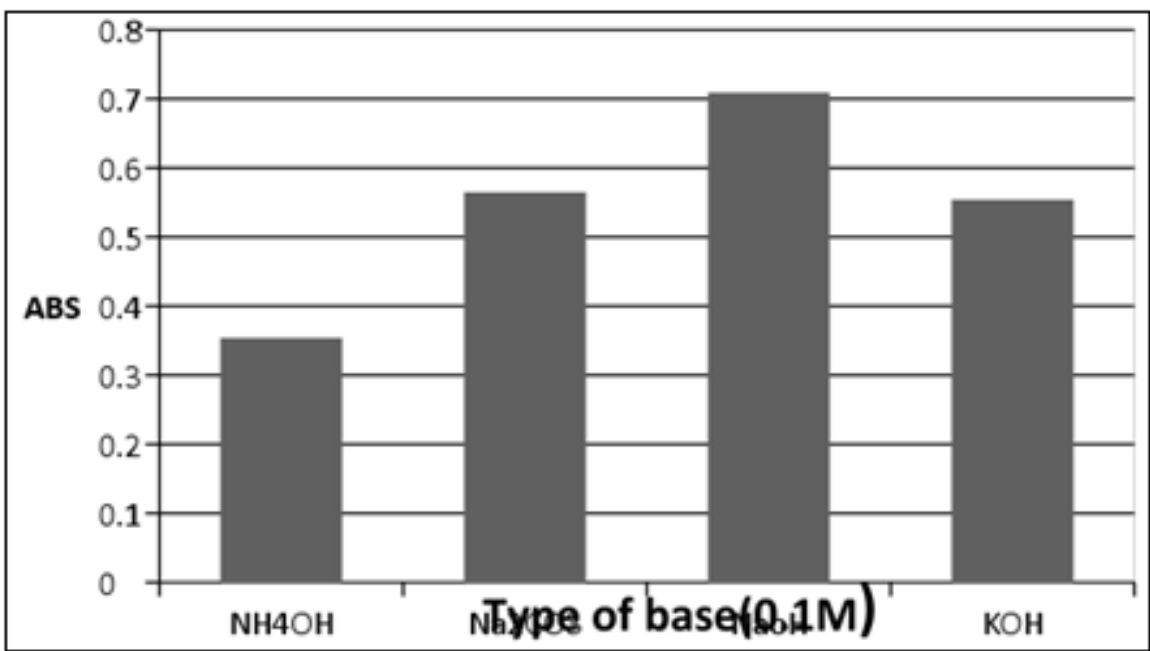

Figure (5a): Effect of type of base

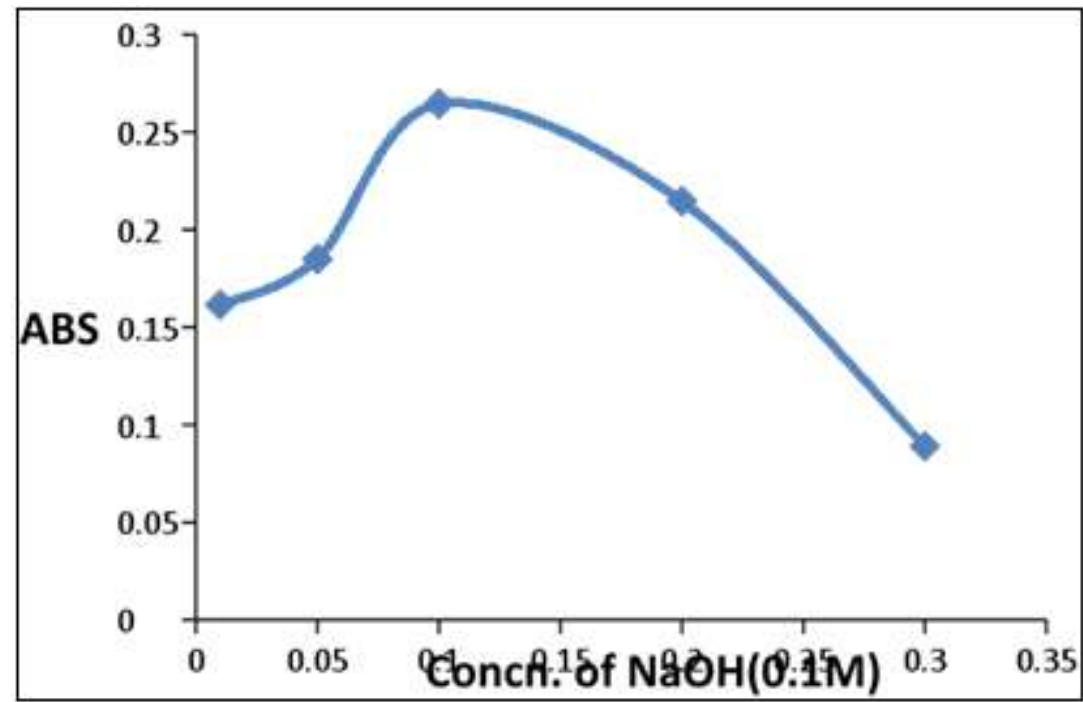

Figure (5b): Effect of concentration of $\mathrm{NaOH}$

Optimization of physical parameter:

The effect of all physical parameters are studies in nFIA and stopped-FIA. The effect of total flow rate on the sensitivity of the colored reaction product was investigated in the range of $\left(0.7-5 \mathrm{ml} \mathrm{min}^{-1}\right)$ for both method (nFIA, sFIA). The results obtained in figure (6) showed that a total flow rate $1.5 \mathrm{ml} \mathrm{min}{ }^{-1}, 2 \mathrm{ml} \cdot \mathrm{min}^{-1}$ gave the highest absorbance in the nFIA method, sFIA method respectively, and was used in this experiment.

The reaction coil Length is an essential parameters that effect on the sensitivity of the colored reaction product in
nFIA and sFIA and was investigated in the range of 25 $250 \mathrm{~cm}$. the results obtained in figure (7) showed that a coil length of $150 \mathrm{~cm}, 75 \mathrm{~cm}$ gave the highest absorbance in nFIA and sFIA, respectively and was used in the experiment.

The injection loop is the other parameters that effects on the sample throuput and was investigated in the range of (74302 microliters). It was found that a loop of 102 microliters gave the highest absorbance for both methods (figure 8). 
International Journal of Science and Research (IJSR)

ISSN (Online): 2319-7064

Index Copernicus Value (2016): 79.57 | Impact Factor (2015): 6.391

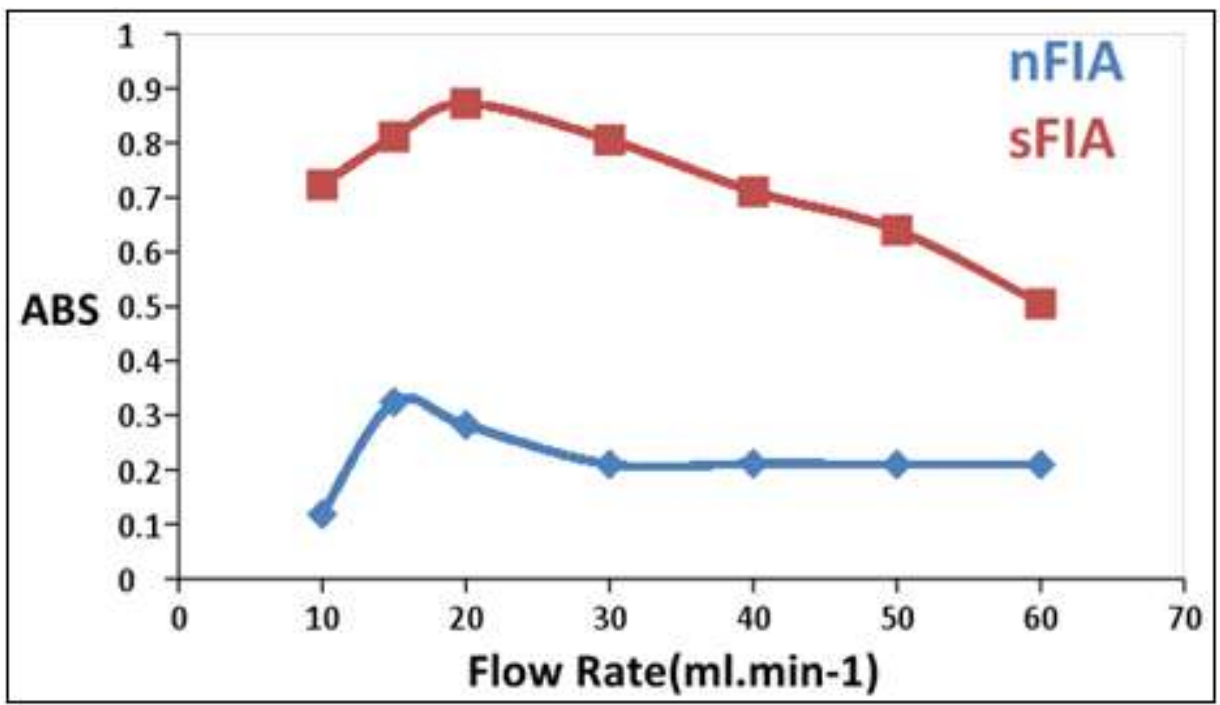

Figure 6: Effect of total flow rate $\left(\mathrm{ml} \cdot \mathrm{min}^{-1}\right)$

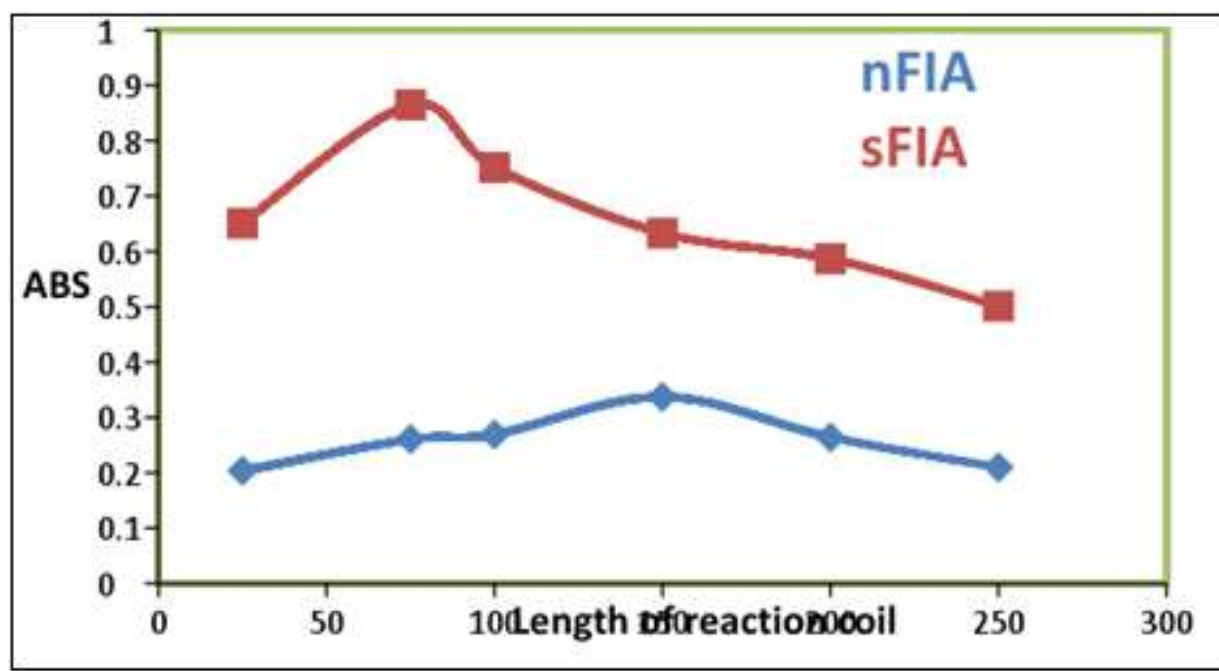

Figure 7: Effect of Reaction coil $(\mathrm{cm})$

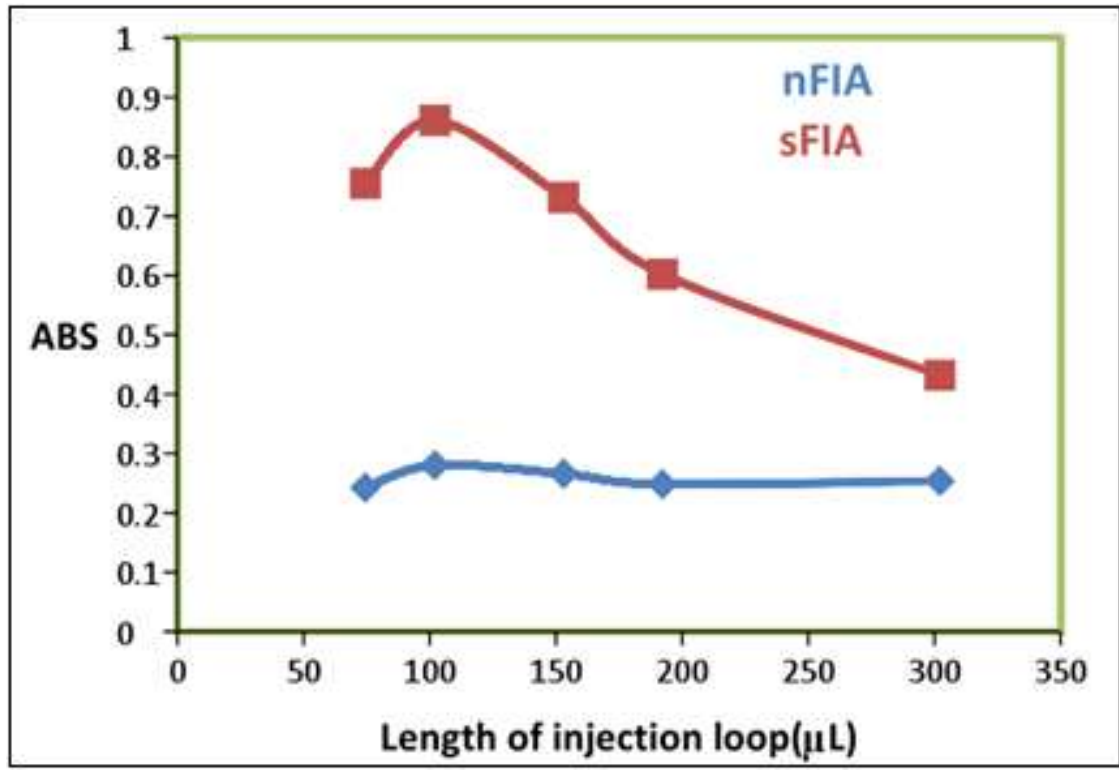

Figure 8: Effect of Length of injection loop(micro liter)

Volume 6 Issue 12, December 2017 www.ijsr.net

Licensed Under Creative Commons Attribution CC BY 


\section{International Journal of Science and Research (IJSR) \\ ISSN (Online): 2319-7064 \\ Index Copernicus Value (2016): 79.57 | Impact Factor (2015): 6.391}

- Calibration Curve in normal flow injection and stopped flow injection

treatments for the calibration curves are summarized in table(2)

After fixing the optimum condition of nFIA for the determination of QRC standard calibration graph were constructed (Figure 9). The analytical values of statistical

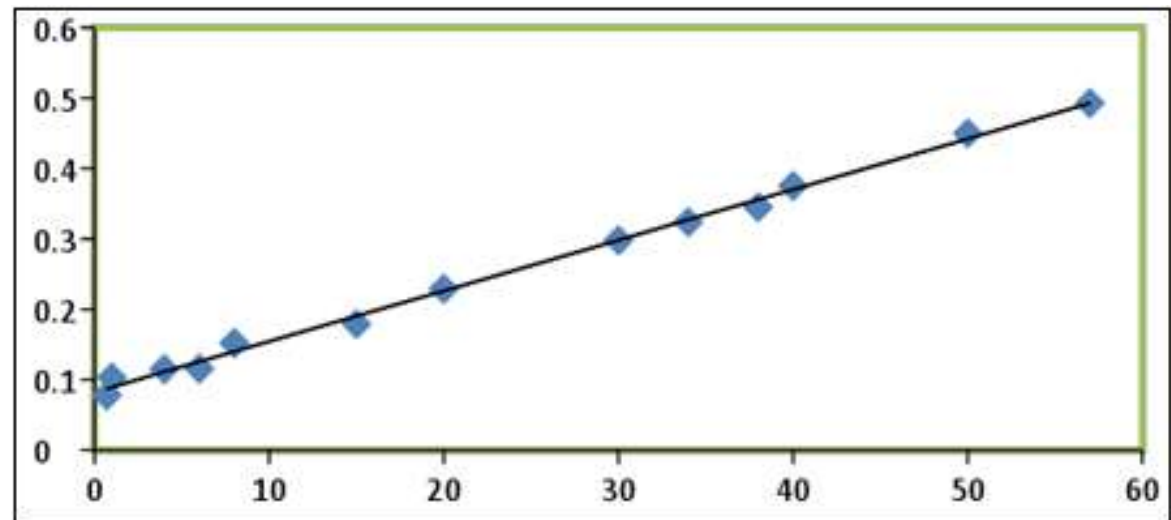

Figure 9: calibration curve for the determination of QRC in normal flow injection analysis

The calibration graph were constructed in sFIA (Figure 10) after study the physical parameters, and the statistical treatment are summarized in Table(2).

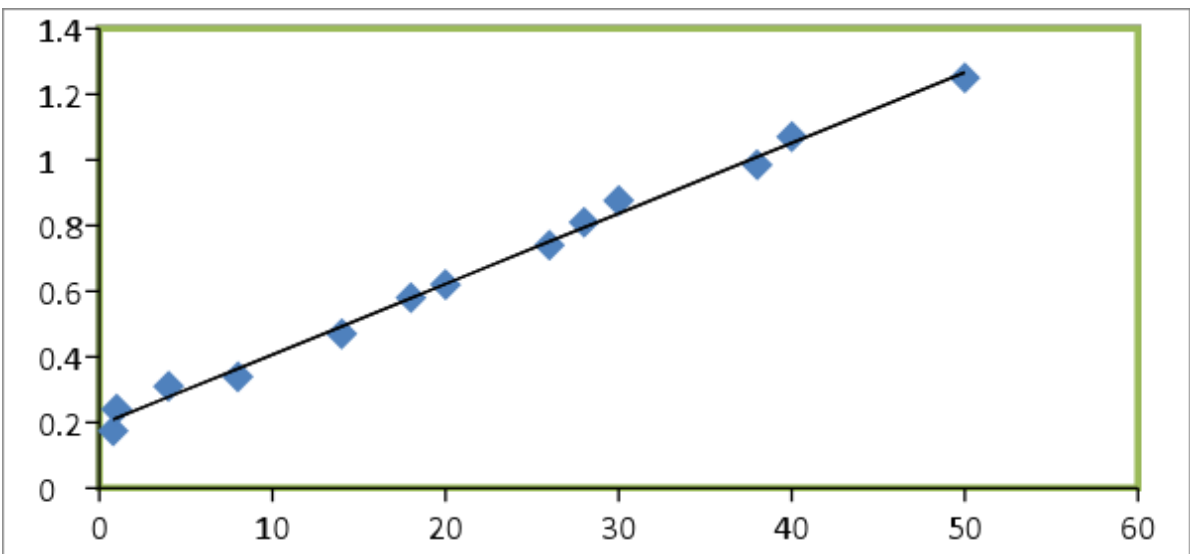

Figure 10: Calibration curve for the determination of QRC in stopped flow injection

Table 2: Analytical values of the calibration graphs for the determination of QRC

\begin{tabular}{|c|c|c|}
\hline Parameters & nFIA procedure & sFIA procedure \\
\hline Regression equation & $Y=0.0072 x+0.0819$ & $Y=0.0215 x+0.1918$ \\
\hline Correlation coefficient & 0.9967 & 0.9947 \\
\hline Reproducibility (\%)(RSD\%) & $<1.528$ & $<1.695$ \\
\hline Recovery \% & $<101.5275$ & $<104.36$ \\
\hline Limit of detection $\left(\mu \mathrm{g} \cdot \mathrm{mL}^{1}\right) ; 3 \mathrm{SDB} / \mathrm{b}$ & 0.4166 & 0.1338 \\
\hline $\begin{array}{c}\text { Limit of detection } \\
\left(\mu \mathrm{g} \cdot \mathrm{mL}^{-1}\right) ; \hat{\mathrm{Y}}=\mathrm{YB}+3 \mathrm{SB}\end{array}$ & 0.04338 & \\
\hline Linearity range & $1-60 \mu \mathrm{g} \cdot \mathrm{ml}^{-1}$ & $0.8-50 \mu \mathrm{g} \cdot \mathrm{ml}^{-1}$ \\
\hline 1.11 & 1.388 & Limit of quantification \\
\hline $3.971 \times 10^{-5}$ & $1.988 \times 10^{-5}$ & Standard deviation of the slope, $\mathrm{Sb}$ \\
\hline $6.319 \times 10^{-3}$ & $5.036 \times 10^{-3}$ & Standard deviation of the intercept, $\mathrm{Sa}$ \\
\hline 0.4651 & 0.0984 & $\begin{array}{c}\text { Sandelle's sensitivity, } \mathrm{S}\left(\mu \mathrm{g} \mathrm{cm}{ }^{-2}\right) \text { per } 0.001 \\
\text { absorbance unit, } \mathrm{S}=\mathrm{M} / \varepsilon\end{array}$ \\
\hline 35 & 70 & Sample through-put $\left(\mathrm{h}^{-1}\right)$ \\
\hline
\end{tabular}

\section{Accuracy and precision}

The accuracy and precision of the method, at three different concentrations, for five replicates of each concentration were tested. The results shown in Table 3 were studied depending upon the value percentage of (E \%), (Rec. \%)and (RSD \%), were obtained. The relative standard deviation (RSD \%) value in all cases indicating good repeatability of the suggested methods.

\section{Volume 6 Issue 12, December 2017}




\section{International Journal of Science and Research (IJSR)}

ISSN (Online): 2319-7064

Index Copernicus Value (2016): 79.57 | Impact Factor (2015): 6.391

Table 3: Accuracy and precision of the proposed method

\begin{tabular}{|c|c|c|c|c|c|}
\hline $\begin{array}{c}\text { Proposed } \\
\text { method }\end{array}$ & \multicolumn{2}{|c|}{$\begin{array}{c}\text { Con.of QRC } \\
\left(\mu \mathrm{g} . \mathrm{ml}^{-1}\right)\end{array}$} & \multirow{2}{*}{$\mathrm{E} \%$} & $\mathrm{Rec} \%$ & \multirow{2}{*}{$\mathrm{RSD} \%$} \\
\cline { 2 - 6 } & present & found & & & \\
\hline \multirow{3}{*}{ nFIA } & 20 & 20.29 & +1.45 & 101.45 & 1.528 \\
\cline { 2 - 6 } & 30 & 29.916 & -0.28 & 99.72 & 0.9556 \\
\cline { 2 - 6 } & 40 & 40.611 & +1.527 & 101.527 & 0.7089 \\
\hline \multirow{3}{*}{ sFIA } & 18 & 18.10 & +0.55 & 100.55 & 1.695 \\
\cline { 2 - 5 } & 26 & 25.49 & -1.96 & 98.04 & 0.854 \\
\cline { 2 - 5 } & 40 & 40.89 & +2.22 & 102.22 & 0.972 \\
\hline
\end{tabular}

\section{Analytical application}

The proposed methods were applied successfully to the analysis of some pharmaceutical preparations containing QRC(the application is quercetin dehydrate, mega quercetin), and they gave a good reproducibility and recoveries as shown in Table 4 . The results obtained by the proposed and reference methods (There are various methods available for estimation of QRC like U.V. HPTLC method reported . not a single U.V. method reported for estimation of quercetin in formulation ((procedure is a spectrophotometric method (preparation of standard stock solution by weighed an accurate amount $100 \mathrm{mg}$ of quercetin dihydrate was dissolved in $20 \mathrm{ml}$ methanol and diluted up to $100 \mathrm{ml}$ by distilled water to obtain $100 \mathrm{mg} / \mathrm{ml}$ concentration of quercetin dihydrate, This solutions was subjected to scanning between $(271 \mathrm{~nm}-372 \mathrm{~nm}))$. present work is done to develop a simple U.V. spectroscopy using normal flow injection method and stopped flow injection method . for capsule forms were compared statistically by means of the F-test and t-test and the proposed methods and the reference methods were found no significant differences in precision and accuracy between the proposed methods and the reference method (Table 5).

Table 4: Application of the proposed methods to the determination of QRC in capsule forms

\begin{tabular}{|c|c|c|c|c|c|c|}
\hline Pharmaceutical preparation & Proposed method & $\begin{array}{l}\text { Present concn } \\
\quad\left(\mu \mathrm{g} \cdot \mathrm{ml}^{-1}\right)\end{array}$ & Found conc $\left(\mu \mathrm{g} \cdot \mathrm{ml}^{-1}\right)$ & $\mathrm{E} \%$ & $\operatorname{Rec} \%$ & RSD\% \\
\hline \multirow{6}{*}{$\begin{array}{c}\text { QRC } \\
100 \mathrm{~g}(3.5302)\end{array}$} & \multirow{3}{*}{ nFIA } & 20 & 19.59 & -2.05 & 97.95 & 1.9176 \\
\hline & & 30 & 30.70 & +2.30 & 102.30 & 0.3764 \\
\hline & & 40 & 40.29 & 0.725 & 100.725 & 0.151 \\
\hline & \multirow[t]{3}{*}{ sFIA } & 18 & 18.10 & +0.55 & 100.55 & 0.073 \\
\hline & & 40 & 40.80 & +2.00 & 102.00 & 0.1493 \\
\hline & & 26 & 25.54 & -1.76 & 98.24 & 0.105 \\
\hline \multirow{6}{*}{$\begin{array}{l}\text { Mega quercetein } \\
(1200 \mathrm{mg} / \text { capsole })\end{array}$} & \multirow[t]{3}{*}{ nFIA } & 20 & 20.29 & +1.45 & 101.45 & 0.2962 \\
\hline & & 30 & 30.15 & +0.50 & 100.50 & 0.4751 \\
\hline & & 40 & 40.36 & +0.90 & 100.90 & 0.5492 \\
\hline & \multirow[t]{3}{*}{ sFIA } & 18 & 18.10 & +0.55 & 100.55 & 0.1286 \\
\hline & & 26 & 25.68 & -1.23 & 98.77 & 0.1102 \\
\hline & & 40 & 40.92 & +2.30 & 102.30 & 0.2282 \\
\hline
\end{tabular}

Table 5: The comparison of the proposed method with standard method

\begin{tabular}{|c|c|c|c|c|c|c|c|}
\hline \multirow[t]{3}{*}{ Pharmaceutical preparation } & \multicolumn{6}{|c|}{ Proposed methods } & \multirow{3}{*}{$\begin{array}{c}\text { Standard method Rf. } \\
\text { Rec } \%\end{array}$} \\
\hline & \multicolumn{3}{|c|}{ nFIA } & \multicolumn{3}{|c|}{ sFIA } & \\
\hline & $\operatorname{Rec} \%$ & $\mathrm{~T}$ & $\mathrm{~F}$ & Rec\% & $\mathrm{T}$ & $\mathrm{F}$ & \\
\hline QRC Pure & 100.585 & \multirow[t]{3}{*}{2.734} & 7.988 & 100.13 & \multirow[t]{3}{*}{2.5561} & 2.415 & 99.699 \\
\hline QRC & 100.125 & & & 100.12 & & & 99.853 \\
\hline \multirow[t]{2}{*}{ Mega quercetin } & 100.975 & & & 100.53 & & & 100.0 \\
\hline & \multicolumn{3}{|c|}{$\begin{aligned} S^{1} 1 & =0.1809, \\
S^{2} 2 & =0.02265 \\
S & =0.319\end{aligned}$} & \multicolumn{3}{|c|}{$\begin{array}{c}S^{1} 1=0.0547 \\
S^{2} 2=0.02265 \\
S=0.9166\end{array}$} & \\
\hline
\end{tabular}

*values at $95 \%$ confidence level, $\mathrm{n} 1=\mathrm{n} 2=3, \mathrm{ttab}=\mathrm{t} 0.05 / 2$ ,n-1= 2.776 where $t$ has

$v=n 1+n 2-2$ degrees of freedom $=4, F \operatorname{Fab}=19.0$ where

F has $v 1=n 1-1, v 2=n 2-1$ degrees of freedom $=2$.

The results obtained by the proposed and standard methods for dosage forms were compared statistically by means of the F-test and t-test at 95\% confidence level [23] and were found the calculated $t$ and F-values (Table 4) did not exceed the theoretical values, which indicates that there is no significant difference between either methods in terms of accuracy and precision F-test, which is defined as testing differences between standard deviations (S1, S2) of data sets, provides a simple method for comparing the precision of two sets of measurements using the following equation:

$$
\mathrm{F}=\mathrm{S} 1 / \mathrm{S} 2 \text { or } \quad \mathrm{F}=\mathrm{S} 2 / \mathrm{S} 1 \quad(\mathrm{~F}<1)
$$

Student's t-Test is an ideal way of comparing the mean one set of measurements with another. The value of t-test is chosen based on the desired confidence level. A $95 \%$ confidence level test is generally used.

\section{Conclusion}

The application of diazotization-coupling reaction of diazotized metoclopramide in sodium hydroxide medium to the spectrophotometric determinations of the quercetin dihydrate in pharmaceutical preparations was described by nFIA and sFIA systems. Although the nFIA system has the advantages of simplicity ,reproducibility, time saving, low reagent consumption need of small sample volume, large dynamic range and high sample throughput. This is important feature of the nFIA system.

The proposed methods offer can be applied to the analysis of a wide concentration range of QRC in real samples with 


\section{International Journal of Science and Research (IJSR) \\ ISSN (Online): 2319-7064 \\ Index Copernicus Value (2016): 79.57 | Impact Factor (2015): 6.391}

satisfactory results. The proposed methods are simple and inexpensive since it requires simple instrumentation.

\section{References}

[1] Croft, K.D. 1998. The chemistry and biological effects of flavonoids and phenolic acids. Ann. New York Acad. of Sci. 854:435-442.

[2] Hertog, M.G.L. and P.C.H. Hollman. 1996. Potential health effects of the dietary flavonol quercetin. Euro. J. Clin. Nutr. 50:63-71.

[3] Keli, S.O., M.G.L. Hertog, E.J.M. Feskens, and D. Kromhout. 1996. Dietary flavonoids, antioxidant vitamins, and incidence of stroke. Arch Intern. Med. 154:637-642.

[4] Knekt, P., R. Järvinen, A. Reunanen, and J. Maatela. 1996. Flavonoid intake and coronary mortality in Finland. BMJ. 312:478-481.

[5] Knekt, P., R. Järvinen, R. Seppänen, M. Heliövaara, L. Teppo, E. Pukkala, and A. Aromaa. 1997. Dietary flavonoids and the risk of lung cancer and other malignant neoplasms. Amer. J. Epidem. 146:223-230.

[6] Leighton, T., C. Ginther, L. Fluss, W.K. Harter, J.Cansado, and V. Notario. 1992. Molecular characterization of quercetin and quercetin glycosides in Allium vegetables phenolic compounds in food and their effects on health II. ACS Symp. Ser. 507:220-238.

[7] H. Sandhar, B. Kumar, S.Prasher, Int pharmaceuticasciencia,2011,(1) 25-41

[8] F. Wang, T. Yao, S. Zeng, Determination of quercetin and kaempferol in human urine after orally administrated tablet of ginkgo biloba extract by HPLC, $J$. Pharm. Biomed. Anal., 33, 317-321 (2003).

[9] K. Ishii, T. Furuta, Y. Kasuya, High-performance liquid chromatographic determination of quercetin in human plasma and urine utilizing solid-phase extraction and ultraviolet detection, J. Chromatogr., B: Anal. Technol. Biomed. Life Sci., 794, 49-56 (2003).

[10] S. Wang S, D. Di, X. Liu, S. Jiang, Determination of luteolin and quercetin in the capsule of Lamiophlomis Rotata (Benth.) Kudo by HPLC coupled with weighted least squares linear regression. J. Liq. Chromatog. Rel. Technol., 30, 1991-1999 (2007).

[11] Y. Zheng, L. Ye, L. Yan, Y. Gao, The electrochemical behavior and determination of quercetin in choline chloride/urea deep eutectic solvent electrolyte based on abra-sively immobilized multi-wall carbon nanotubes modified electrode, Int. J. Electrochem. Sci., 9, 238-248 (2014).

[12]L. Wang, M. E. Morris, Liquid chromatography-tandem mass spectroscopy assay for quercetin and conjugated quercetin metabolites in human plasma and urine, $J$. Chromatogr. B, 821, 194-201 (2005).

[13]N. Pejić, V. Kuntić, Z. Vujić, S. Mićić, Direct spectrophotometric determination of quercetin in the presence of ascorbic acid, Il Farmaco, 59, 21-24 (2004).

[14] V. Kuntić, N. Pejić, S. Mićić, V. Vukojević, Z. Vujić, D. Malešev, Determination of quercetin in pharmaceutical formations via its reaction with potassium titanyloxalate. Determination of the stability constants of the quercetin titanyloxalato complex, $J$. Serb. Chem. Soc., 70, 753-763 (2005).
[15] G. J. Volikakis, C. E. Efstathiou, Fast screening of total flavonols in wines, tea-infusions and tomato juice by flow injection/adsorptive stripping voltammetry, Anal. Chim. Acta, 551, 124-131 (2005).

[16] S. U. Rakesh, P. R. Patil, V. R. Salunkhe, P. N. Dhabale, K. B. Burade, HPTLC method for quantitative determi-nation of quercetin in hydroalcoholic extract of dried flower of Nymphaea stellata Wild, Int. J. ChemTech Res., 1, 931-936 (2009).

[17] M. Shaghaghi, J. L. Manzoori, A. Jouyban. Determination of total phenols in tea infusions, tomato and apple juice by terbium sensitized fluorescence method as an alternative approach to the Folin-Ciocalteu spectrophotometric method, Food Chem., 108, 695-701 (2008).

[18] M. Oman, M. Škerget, Ț. Knez, Application of supercritical fluid extraction for the separation of nutraceuticals and other phytochemicals from plant material, Maced. J. Chem. Chem. Eng., 32, 183-226 (2013).

[19] Al-Bayati ,Y. K. and Aljabari, F. I. 2016.Synthesis of ibuprofen-molecularly imprinted polymers used as sensors to determine drug in pharmaceutical preparation. Asian J. of Chemistry, 28(6), pp:13761380.

[20] J. Ruzicka, and E. H. Hasan, "Flow Injection Analysis" , $3^{\text {rd }}$ Ed., John Wiley and Sons, Inc., New York, 2005.

[21] J. Ruzicka, and E. H. Hasan, "Flow Injection Analysis" , $2^{\text {rd }}$ Ed., John Wiley \& Sons, New York, 1988, p156-166.

[22] K. Grudpan, P. Ampan, Y. Udnan, S. Jayasvati, S. Lapanan tnoppakhun, J. Jakmunee, G.D. Christian, J. Ruzicka, Talanta 58 (2002) 1319.

[23] Miller, J. N. and Miller, J. C. 2000. Statistics and Chemometrics for Analytical Chemistry. Fourth Edition. Pearson Education Limited, London. 